\title{
A case of pulmonary sequestration with Aspergillus species infection presenting as an enlarged right paratracheal mass
}

\author{
S. Lohani, MD, MRCP, ${ }^{a}$ R. Varma, MD, MRCP, ${ }^{\text {b }}$ and B. Leahy, FRCP, ${ }^{b}$ Manchester, United Kingdom
}

W e present the case of a 45-year-old man who was incidentally found to have enlarged right paratracheal opacity on a chest radiograph and computed tomographic (CT) scan. Biopsy revealed invasive Aspergillus species infection. Ultimately, a thoracotomy was carried out because the abnormality persisted despite antifungal treatment, and it was found to be a sequestered lung segment.

\section{Clinical Summary}

A 45-year-old white man presented to his general practitioner with a few weeks' history of cough with green sputum and an episode of hemoptysis. A chest radiograph showed features of right paratracheal enlargement, and he was subsequently referred to the Chest Diseases unit at Trafford General Hospital.

While attending the clinic, he had recovered from his "lower respiratory tract infection" and was asymptomatic. He had never smoked in his life. Apart from a history of gout, he had previously been healthy. Subsequent systemic evaluation was unremarkable. There was no palpable lymph node or hepatosplenomegaly.

A CT scan (Figure 1) of the chest showed a large necrotic paratracheal lymph node mass measuring $4.7 \times 4.3 \mathrm{~cm}$. There was no other abnormality, and the liver, adrenal glands, and spleen were normal. The result of the C-reactive protein assay was less than $1 \mathrm{mg} / \mathrm{L}$.

This patient was then referred for mediastinoscopy. The results and the histology were inconclusive, showing sinus histiocytosis. In the meantime, the repeat chest radiograph showed that the right paratracheal mass was enlarging. Subsequently, a right anterior mediastinostomy was carried out. A mass was seen lying behind the superior vena cava.

It was described as very soft, and on aspiration, pus came out, which was sent for culture. A significant biopsy of the mass was taken, and a strand of cartilage was seen crossing through the middle of the mass. There did not appear to be any communication with the airway.

The pus grew Aspergillus fumigatus. Biopsy showed chronic inflammation. Portions of cartilage with mature bone were seen. There was no evidence of neoplasia.

After this, the subject was started on oral itraconazole. Subsequent checks on immunoglobin levels, immunoglobin subclasses,

From Wythenshawe Hospital ${ }^{\mathrm{a}}$ and Trafford General Hospital, ${ }^{\mathrm{b}}$ Manchester, United Kingdom.

Received for publication Oct 15, 2004; accepted for publication Nov 17, 2004.

Address for reprints: S. Lohani, MD, Webb House, Stott Lane, Salford, United Kingdom M6 8WH (E-mail: sdlohani@aol.com)

J Thorac Cardiovasc Surg 2005;129:1459-60

$0022-5223 / \$ 30.00$

Copyright $\odot 2005$ by The American Association for Thoracic Surgery

doi:10.1016/j.jtcvs.2004.11.024

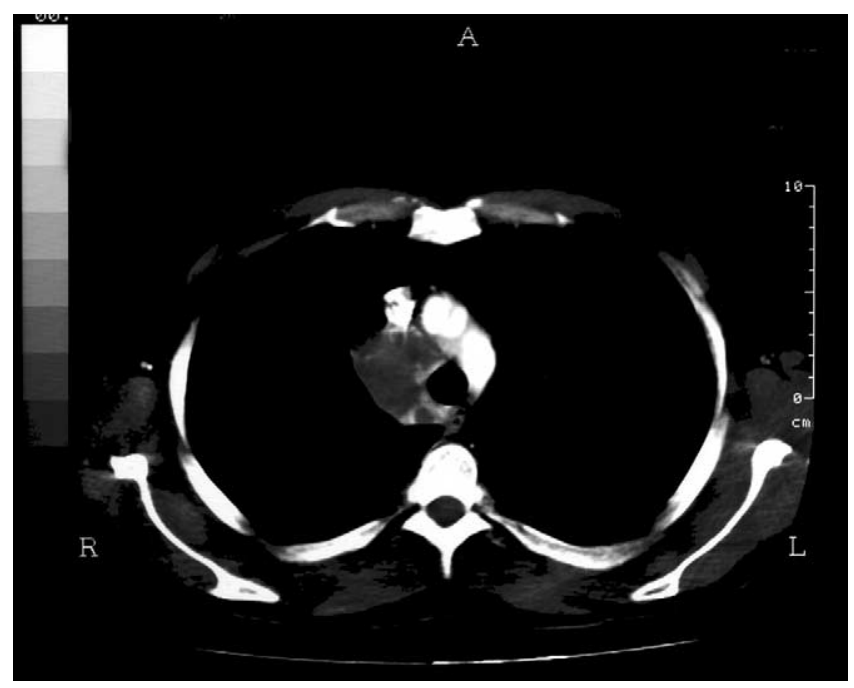

Figure 1. CT of the chest showing a right paratracheal mass.

and CD4 counts were normal apart from a mildly increased $\operatorname{IgA}$ level of $5.5 \mathrm{~g} / \mathrm{L}$ (normal, 0.89-4.46 g/L). The results of his Aspergillus species precipitin tests were strongly positive.

Although the patient remained well throughout the illness and the treatment, a repeat CT scan about 7 months after the initiation of treatment did not show any change in the right paratracheal lymph node shadow. He was therefore referred for further surgical evaluation.

Subsequently, a thoracotomy was carried out that showed a boggy mass lying medial to the upper lobe in the right paratracheal area. The mass went down to a bronchus arising directly from the trachea above the azygos vein. This was supplied by a branch from the right subclavian artery. It contained glary mucinous fluid and was a sequestered segment. Subsequent histology also confirmed the diagnosis of pulmonary sequestration.

\section{Discussion}

The term pulmonary sequestration was coined by Pryce in 1946 to describe a "disconnected bronchopulmonary mass with an anomalous systemic arterial supply."1

Pulmonary sequestration is a congenital anomaly in which an aberrant systemic artery, usually arising from the thoracic or upper abdominal aorta, supplies part of the lungs, usually the lower lobe. ${ }^{2}$ They are rare and usually present in early childhood with recurrent chest infection. In a series from Children's National Medical Center in Washington, 20 cases of pulmonary sequestration were described over 25 years. $^{3}$

This does represent an area of compromised local immunity and is obviously a fertile ground for opportunistic infection. It 
seems that our patient had a low-grade Aspergillus species infection in the sequestered lung segment in the right paratracheal region. Because the mass persisted despite itraconazole therapy, excision was requested.

So far as we are aware, this is a unique case of pulmonary sequestration presenting as a right paratracheal mass with Aspergillus species infection. During literature review, we came across a case of pulmonary sequestration presenting as a retroperitoneal mass described by Nelson, Blum, and Cook, ${ }^{4}$ suggesting that pulmonary sequestration can manifest in unusual forms.

\section{References}

1. Pryce DM. Lower accessory pulmonary artery with intralobar sequestration of lung: a report of seven cases. J Pathol. 1946;58:457-67.

2. Khalil KG, Kilman JW. Pulmonary sequestration. J Thorac Cardiovasc Surg. 1975;70:928-37.

3. Schwartz MZ, Ramachandran P. Congenital malformations of the lung and mediastinum - a quarter century of experience from a single institution. J Pediatr Surg. 1997;32:44-7.

4. Nelson JB, Blum MD, Cook WA. Retroperitoneal pulmonary sequestration: a rare congenital anomaly in a 71 year old man. $J$ Urol. 1994;152(suppl):2341-3.

\section{THORACIC SURGERY FOUNDATION FOR RESEARCH AND EDUCATION 2005 RESEARCH AWARD RECIPIENTS}

\section{TSFRE RESEARCH FELLOWSHIP}

Madison C. Cuffy, MD—“"The Role of Indoleamine 2,3 Dioxygenase on Modulating Immune Responses in Inflammatory Arterial Diseases," Yale University School of Medicine

Andrew J. Kaufman, MD_-"Functional Analysis of Squamous Cell Carcinoma Related Oncogene (SCCRO) in the Sonic Hedgehog Pathway," Memorial Sloan-Kettering Cancer Center

Tom C. Nguyen, MD_-"Biomechanics of the Cardiac Support Device in Heart Failure: New Answers to an Old Problem," Stanford University

Hisasha Sahara, MD_-"Indirect Recognition of Collagen (Type V) in the Pathogenesis of Lung Allograft Rejection," Massachusetts General Hospital, Harvard Medical School

\section{TSFRE RESEARCH GRANT}

Ara A. Vaporciyan, MD_"Effect of Inflammatory Gene Polymorphism in the Development of Atrial Fibrillation After Pulmonary Resection," University of Texas, M.D. Anderson Cancer Center

\section{NINA STARR BRAUNWALD RESEARCH FELLOWSHIP}

Barbara L. Robinson, MD_-"The Stunned Heart and Cardiac Surgery: Apoptosis/Necrosis and the Role of Heat Shock Proteins,” Boston Children's Hospital 